This item was submitted to Loughborough's Research Repository by the author.

Items in Figshare are protected by copyright, with all rights reserved, unless otherwise indicated.

\title{
Blood pressure reactivity to psychological stress is associated with clinical outcomes in patients with heart failure
}

PLEASE CITE THE PUBLISHED VERSION

https://doi.org/10.1016/j.ahj.2017.07.003

\section{PUBLISHER}

(C) Elsevier

\section{VERSION}

AM (Accepted Manuscript)

\section{PUBLISHER STATEMENT}

This work is made available according to the conditions of the Creative Commons Attribution-NonCommercialNoDerivatives 4.0 International (CC BY-NC-ND 4.0) licence. Full details of this licence are available at: https://creativecommons.org/licenses/by-nc-nd/4.0/

\section{LICENCE}

CC BY-NC-ND 4.0

\section{REPOSITORY RECORD}

Sherwood, Andrew, LaBarron K. Hill, James A. Blumenthal, Kirkwood F. Adams, Nicola Paine, Gary G. Koch, Christopher M. O'Connor, Kristy S. Johnson, and Alan L. Hinderliter. 2017. "Blood Pressure Reactivity to Psychological Stress Is Associated with Clinical Outcomes in Patients with Heart Failure". Loughborough University. https://hdl.handle.net/2134/26502. 


\section{Accepted Manuscript}

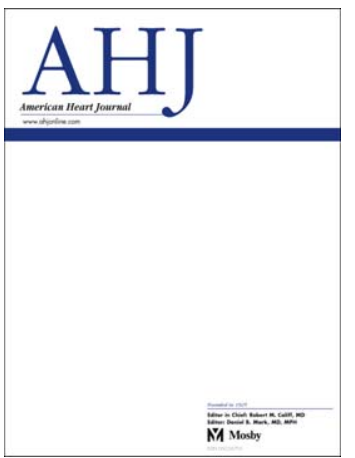

Blood Pressure Reactivity to Psychological Stress is Associated with Clinical Outcomes in Patients with Heart Failure

Andrew Sherwood PhD, LaBarron K. Hill PhD, James A. Blumenthal $\mathrm{PhD}$, Kirkwood F. Adams Jr MD, Nicola J. Paine PhD, Gary G. Koch PhD, Christopher M. O’Connor MD, Kristy S. Johnson MPH, Alan L. Hinderliter MD

PII: $\quad$ S0002-8703(17)30201-6

DOI: $\quad$ doi: $10.1016 / j . a h j .2017 .07 .003$

Reference: $\quad$ YMHJ 5478

To appear in: American Heart Journal

Received date: $\quad 17$ May 2017

Accepted date: 7 July 2017

Please cite this article as: Sherwood Andrew, Hill LaBarron K., Blumenthal James A., Adams Jr Kirkwood F., Paine Nicola J., Koch Gary G., O'Connor Christopher M., Johnson Kristy S., Hinderliter Alan L., Blood Pressure Reactivity to Psychological Stress is Associated with Clinical Outcomes in Patients with Heart Failure, American Heart Journal (2017), doi: 10.1016/j.ahj.2017.07.003

This is a PDF file of an unedited manuscript that has been accepted for publication. As a service to our customers we are providing this early version of the manuscript. The manuscript will undergo copyediting, typesetting, and review of the resulting proof before it is published in its final form. Please note that during the production process errors may be discovered which could affect the content, and all legal disclaimers that apply to the journal pertain. 


\title{
Blood Pressure Reactivity to Psychological Stress is Associated with Clinical Outcomes in Patients with Heart Failure
}

\author{
Andrew Sherwood $\mathrm{PhD}^{1}$, LaBarron K. Hill $\mathrm{PhD}^{1}$, James A. Blumenthal $\mathrm{PhD}^{1}$, \\ Kirkwood F. Adams Jr, MD², Nicola J. Paine PhD ${ }^{1}$, Gary G. Koch, PhD ${ }^{3}$, \\ Christopher M. O’Connor, MD ${ }^{1}$, Kristy S. Johnson, MPH ${ }^{1}$, Alan L. Hinderliter, MD
}

Short Title: Blood Pressure Reactivity in Heart Failure

${ }^{1}$ Duke University Medical Center, Durham, NC, USA (AS, LKH, JAB, NJP, CMO) ${ }^{2}$ University of North Carolina School of Medicine, Chapel Hill, NC, USA (KFA, ALH), ${ }^{3}$ University of North Carolina School of Public Health, Chapel Hill, NC, USA (GGK).

Total Word Count: 4,153

Tables: 6

Figures: 2

Corresponding Author: Dr. Andrew Sherwood, Box 3119, Duke University Medical Center, Durham, NC 27710. E-mail sherw002@mc.duke.edu Phone: 919-684-8835 Fax: 919-684-8629

Conflict(s) of Interest Statement: None 


\begin{abstract}
INTRODUCTION: Cardiovascular (CV) reactivity to psychological stress has been implicated in the development and exacerbation of cardiovascular disease (CVD). Although high CV reactivity traditionally is thought to convey greater risk of CVD, the relationship between reactivity and clinical outcomes is inconsistent, and may depend on the patient population under investigation. The present study examined CV reactivity in patients with heart failure (HF) and its potential association with longterm clinical outcomes.
\end{abstract}

METHODS: 199 outpatients diagnosed with HF, with ejection fraction $\leq 40 \%$, underwent an evaluation of blood pressure (BP) and heart rate reactivity to a laboratory-based simulated public-speaking stressor. Cox proportional hazards regression models were used to examine the prospective association between $\mathrm{BP}$ and heart rate reactivity on a combined endpoint of death or CV hospitalization over a 5-year median follow-up period.

RESULTS: Both systolic blood pressure (SBP) and diastolic blood pressure (DBP) reactivity, quantified as continuous variables, were inversely related to risk of death or CV hospitalization (p's $<.01)$ after controlling for established risk factors, including HF disease severity, etiology, and age. In similar models, heart rate reactivity was unrelated to outcome $(\mathrm{p}=0.12)$. In models with tertiles of reactivity, high SBP reactivity, compared to intermediate SBP reactivity, was associated with lower risk $($ Hazard Ratio = $.498,95 \%$ CI $[.335, .742], \mathrm{p}=.001)$; while low SBP reactivity did not differ from intermediate reactivity. For DBP, high reactivity was marginally associated with lower risk compared to intermediate DBP reactivity $(\mathrm{HR}=.767,95 \%$ CI $[.515,1.14], \mathrm{p}=.193)$, while low DBP reactivity was associated with greater risk $(\mathrm{HR}=1.49,95 \% \mathrm{CI}[1.027,2.155], \mathrm{p}=.0359)$. No relationship of heart rate reactivity to outcome was identified.

CONCLUSIONS: For HF patients with reduced ejection fraction, a robust increase in BP evoked by a laboratory-based psychological challenge was associated with lower risk for adverse CVD events, and 
may be a novel and unique marker of left ventricular systolic reserve that is accompanied by a more favorable long-term prognosis.

Key words: heart failure; stress; blood pressure reactivity; hospitalizations; death. 

ABBREVIATIONS:
BDI - Beck Depression Inventory
BP - Blood Pressure
CABG - Coronary Artery Bypass Graft Surgery
CHD - Coronary Heart Disease
CVD - Cardiovascular Disease
DBP - Diastolic Blood Pressure
HF - Heart Failure
HR - Hazard Ratio

LVEF - Left Ventricular Ejection Fraction

NT-proBNP - N-Terminal pro B-type Natriuretic Peptide

PCI - Percutaneous Coronary Intervention

SBP - Systolic Blood Pressure

SNS - Sympathetic Nervous System 
Exaggerated cardiovascular (CV) responses to stress have long been considered as potentially deleterious to cardiovascular health. Although this notion has been entertained and supported by anecdotal evidence since antiquity, its foundation as a scientific concept did not arise until the beginning of the $20^{\text {th }}$ century (1). In general, acute psychological stress is associated with "fight/flight" mobilization of the CV system via sympathetic nervous system (SNS) activation, typically resulting in a marked increase in blood pressure (BP). Laboratorybased evaluation of "cardiovascular reactivity" is one strategy that has been widely adopted to help understand the implications of individual differences in the magnitude of the stress response for CV health (2-6). Reactivity is typically defined by changes in CV responses compared to resting levels during psychological stress. Prospective studies have shown that relatively healthy men and women exhibiting greater BP reactivity are at increased risk for the development of hypertension and atherosclerotic cardiovascular disease (CVD), compared to those who exhibit a less pronounced response (4). In patients with ischemic heart disease (IHD), high BP reactivity to laboratory mental stressors has been linked to an increased incidence of myocardial ischemia and greater risk for untoward cardiac events $(7,8)$.

To our knowledge, only one study to date has examined the association of $\mathrm{CV}$ reactivity with clinical outcomes in patients with heart failure (HF). Kupper and colleagues examined the association between BP responses to a laboratory-based, simulated public speaking task and mortality over a 4-year follow-up period in 100 patients with systolic HF (9). High BP reactivity was not associated with increased mortality risk, while individuals who exhibited low diastolic blood pressure (DBP) responses had a twofold increased risk of mortality compared to those who exhibited intermediate DBP responses. The present study was designed to further examine the relation of $\mathrm{CV}$ reactivity to mental stress to adverse clinical outcomes in patients with HF. 
Utilizing a simulated public speaking mental challenge, we also examined the association between BP and heart rate reactivity and a composite endpoint of CV hospitalization or death over a median 5-year follow-up period in patients with $\mathrm{HF}$ and reduced ejection fraction (EF).

\section{METHODS}

\section{Participants}

Participants were recruited from the HF clinics at Duke University Medical Center and the University of North Carolina at Chapel Hill, from January 2000 through December 2002. Approximately 500 patients that met our eligibility criteria were approached; 219 of these patients consented to participate and were enrolled. For 204 of these participants we obtained a plasma NT-proBNP value necessary to control for HF disease severity in our analyses, and of these 204 we completed cardiovascular reactivity testing on 199, which comprise the present study sample. Inclusion criteria for study participation were HF with New York Heart Association Class II-III symptoms of at least 3-months duration; and left ventricular ejection fraction (LVEF) of $40 \%$ or less as assessed by left ventriculography, nuclear gated blood pool or perfusion study, or echocardiography, within 6 months of study enrollment. Potential participants were excluded if they were pacemaker-dependent, had uncontrolled hypertension (BP > 180/105 $\mathrm{mm} \mathrm{Hg}$ ), experienced a myocardial infarction (MI) within the past 3 months, or underwent percutaneous coronary intervention (PCI) or coronary artery bypass graft surgery (CABG) within the past 3 months, had HF due to a condition other than ischemic or non-ischemic dilated cardiomyopathy, such as uncorrected primary valvular disease or hypertrophic or restrictive cardiomyopathy, had uncorrected thyroid heart disease, had a persistent tachyarrhythmia, or had a life limiting or complicated illness including cancer, renal dysfunction, hepatic dysfunction, or 
dementia. Participants who were pregnant, had atrial fibrillation, reported alcohol or drug abuse within 12 months, or were unable to comply with the assessment procedure or to provide informed consent were excluded. The study was approved by the Institutional Review Board at Duke University Medical Center, where all assessments were performed. Written informed consent was obtained from all participants before their participation.

\section{Clinical Status}

Clinical information and medical history were obtained from medical records.

Medications were documented as medications being taken at the time of baseline assessments.

\section{N-Terminal pro B-type Natriuretic Peptide (NT-proBNP)}

Blood was collected from an antecubital vein into a phlebotomy tube containing EDTA. Samples were placed on ice, cold-centrifuged at $1000 \mathrm{X}$ g for $10 \mathrm{~min}$. NT-proBNP

measurements were performed using an electrochemiluminescence immunoassay in accordance with the manufacturer's instructions (Elecsys ${ }^{\circledR}$ proBNP, Roche Diagnostics Corporation, Indianapolis, IN).

\section{Left Ventricular Ejection Fraction (LVEF)}

LVEF was determined by two-dimensional echocardiography. Apical 4-chamber and 2chamber images of the heart were acquired by a single sonographer using an Acuson (Mountain View, California) ultrasound machine and were stored as digital loops. The endocardial borders of the LV in the 2 views were traced by a single experienced echocardiography specialist using customized off-line software (Access Point 2000, Freeland Systems, LLC, Westfield, Indiana), and ventricular volumes and LVEF were computed using the biapical Simpson's rule. 


\section{Depression Symptoms}

Depression symptoms were assessed using the Beck Depression Inventory (BDI), a 21item self-report measure $(10,11)$. Elevated symptoms of depression measured by the BDI are associated with increased risk of adverse events in patients with $\operatorname{HF}(12,13)$.

\section{Blood Pressure (BP) and Heart Rate}

BP was assessed using a Suntech 4240 blood pressure monitor, which determined systolic (SBP) and diastolic (DBP) blood pressure during the testing protocol. This computer-based monitor measures heart rate using a standard electrocardiogram.

\section{Mental Stress Testing}

Resting Baseline: During the first 20 minutes, BP measurements were initiated every 5 minutes to acclimatize participants to the BP cuff. During the last 5 minutes of the baseline rest period BP and heart rate were recorded every minute, resulting in a total of five sets of readings that were averaged (mean) to represent resting baseline.

Public Speaking Task: Participants were asked to choose one of the following topics to discuss during a 3-minute speech: (i) Does the healthcare system in the U.S. need to be changed? (ii) Who or what is to blame for the epidemic of school shootings? (iii) Is the death penalty needed in modern America? Participants were allowed 3 minutes to prepare their speech, without making written notes. Subsequently, participants presented their speech for 3-minutes to a research staff member who was seated in the room with them, with participants also instructed that a video camera and intercom system would allow others members of the research team outside the testing room to see and hear their speech. BP and heart rate were measured once per minute over the 3-minute speech task, and BP and heart rate reactivity were defined as the difference between resting baseline and the mean of the three speech values. 


\section{Long-term Follow-up of Vital Status and Hospitalizations}

Participants' medical records were reviewed on a yearly basis, over a median period of 5 consecutive years from baseline (with a range of 4 to 7 years and no losses to follow-up), on the anniversary of their baseline assessments. Patients also were contacted annually by mail and asked to indicate whether they had been hospitalized during the past year, and to provide consent for retrieval of their hospitalization records. The primary endpoint was defined as the time to cardiovascular hospitalization or death (whichever occurred first) within the follow-up period. Patient mortality was verified through hospital and Emergency Medical Services records. Cardiovascular hospitalizations included hospitalizations for MI, stroke, worsening HF, PCI, cardiac surgery including $\mathrm{CABG}$, and heart transplantation.

\section{Statistical Methods}

Cox proportional hazards regression models were used to examine the relationship between cardiovascular reactivity (BP and heart rate responses to public speaking, specified as continuous variables) and events (mortality and hospitalizations) during the follow-up period. HF etiology (ischemic or non-ischemic), NT-proBNP, LVEF, age, and BDI score were evaluated in the originally planned models, together with resting baseline BP and heart rate values. In order to assess the robustness of the planned models, other potential factors (including NYHA class, diabetes, hypertension, hypercholesterolemia, myocardial infarction, smoker, glomerular filtration rate, defibrillator, beta-blocker, diuretic, angiotensin converting enzyme (ACE)inhibitor, nitrate, warfarin, statin) were eligible for entry into the models by stepwise selection ( $\mathrm{SLE}=.1)$. In order to better understand associations with continuous variables, the regression models were re-fit using BP and heart rate responses classified into low, intermediate, and high 
tertiles of reactivity. For Cox regression analyses, NT-proBNP was expressed as NT-

proBNP/1000, LVEF was expressed as LVEF/10, SBP was expressed as SBP/10, DBP as $\mathrm{DBP} / 10$, heart rate as heart rate/10, and age was expressed as age/10. Kaplan-Meier plots were constructed to illustrate the association between tertiles of BP reactivity indices (SBP and DBP) and event free survival.

\section{Sources of Funding}

This work was supported by Grants HL61784 and HL121708 from the National Heart, Lung, and Blood Institute, and grant M01-RR-30 from the General Clinical Research Center program, National Center for Research Resources, National Institutes of Health.

\section{Author Contributions}

The authors are solely responsible for the design and conduct of this study, all study analyses, the drafting and editing of the paper and its final contents

\section{RESULTS}

\section{Sample Demographics and Outcomes}

Table 1 summarizes the demographic and clinical characteristics of our study sample. At the time of our baseline study assessments, participants had been living with a diagnosis of HF for an average of $5.3 \pm 4.8$ years. Over the median follow up period of 5 years, there was a total of 155 first events ( $82 \%$ of the sample), including 72 CVD hospitalizations and 83 deaths. It is of note that there were no missing data for the study sample and no participants were lost to follow-up. 
Table 1. Demographic and clinical characteristics of the Study Sample

\begin{tabular}{|c|c|}
\hline Characteristic (N=199) & Mean \pm SD or $\%$ \\
\hline Age (years) & $57.0 \pm 12.2$ \\
\hline Body Mass Index $\left(\mathrm{kg} / \mathrm{m}^{2}\right)$ & $31.3 \pm 6.9$ \\
\hline Race (\% White) & $50 \%$ \\
\hline Gender (\% Female) & $32 \%$ \\
\hline BDI Depression Score & $10.7 \pm 7.3$ \\
\hline NR-proBNP (pg/ml) & $1717.0 \pm 2716.5$ \\
\hline LVEF & $31.9 \pm 11.4$ \\
\hline Baseline SBP (mmHg) & $99.9 \pm 18.4$ \\
\hline Baseline DBP (mmHg) & $60.8 \pm 10.7$ \\
\hline Baseline Heart Rate (bpm) & $66.5 \pm 11.5$ \\
\hline SBP Reactivity (mmHg) & $19.4 \pm 14.3$ \\
\hline DBP Reactivity (mmHg) & $14.7 \pm 9.2$ \\
\hline Heart Rate Reactivity (bpm) & $6.5 \pm 6.0$ \\
\hline Etiology ( \% ischemic) & 43.5 \\
\hline Beta Blocker (\% usage) & 87.5 \\
\hline Diabetes (\%) & 44.0 \\
\hline Current Smoker (\%) & 16.5 \\
\hline Current Alcohol use (\%) & 22.8 \\
\hline Anti-coagulant $(\%)$ & 29.0 \\
\hline Antidepressant (\%) & 20.5 \\
\hline Cholesterol Medication (\%) & 46.5 \\
\hline Implantable Defibrillator (\%) & 7.5 \\
\hline Diuretic (\%) & 92.5 \\
\hline ACE inhibitor (\%) & 86.5 \\
\hline Pacemaker (\%) & 28.5 \\
\hline
\end{tabular}

Associations between reactivity to stress and death or cardiovascular hospitalization

Systolic Blood Pressure (SBP) Reactivity.

Cox Proportional Hazards Regression Models (Table 2) in which SBP reactivity was specified as a continuous variable revealed that increasing SBP reactivity to public speaking was associated with reduced incidence of death or cardiovascular hospitalization (HR, 0.859; 95\% CI, $0.765-0.965 ; p=0.01)$ in models which included etiology, LVEF, NT-proBNP and resting SBP. Extended models which also included depression and use of diuretics still revealed 
elevated SBP reactivity to stress to be associated with a lower risk of death or cardiac event (HR, $0.860 ; 95 \%$ CI, $0.765-967 ; p=0.012)$.

Table 2. Systolic Blood Pressure Response to Mental Stress: Cox Proportional Regression Analyses for Death or Cardiac Hospitalization

\begin{tabular}{|lcccc|}
\hline Variable & $\begin{array}{c}\text { Planned } \\
(\mathbf{9 5 \%} \mathbf{C I})\end{array}$ & P Value $^{*}$ HR & $\begin{array}{c}\text { Extended Model }^{\dagger} \text { HR } \\
(\mathbf{9 5 \%} \text { CI })\end{array}$ & P Value \\
\hline Etiology & $1.713(1.241-2.366)$ & $\mathbf{0 . 0 0 1}$ & $1.759(1.273-2.429)$ & $\mathbf{0 . 0 0 1}$ \\
LVEF/10 & $0.829(0.706-0.973)$ & $\mathbf{0 . 0 2 2}$ & $0.808(0.686-0.951)$ & $\mathbf{0 . 0 1 1}$ \\
ProBNP/1000 & $1.060(1.011-1.111)$ & $\mathbf{0 . 0 1 6}$ & $1.069(1.019-1.122)$ & $\mathbf{0 . 0 0 7}$ \\
Baseline SBP/10 & $1.016(0.923-1.115)$ & 0.731 & $1.033(0.992-1.133)$ & 0.485 \\
SBP Reactivity/10 & $0.859(0.765-0.965)$ & $\mathbf{0 . 0 1 0}$ & $0.860(0.765-0.967)$ & $\mathbf{0 . 0 1 2}$ \\
Depression & - & - & $1.034(1.012-1.056)$ & $\mathbf{0 . 0 0 2}$ \\
Diuretics & - & - & $2.161(1.053-4.436)$ & $\mathbf{0 . 0 3 6}$ \\
\hline
\end{tabular}

$\mathrm{HR}=$ Hazard ratio; $\mathrm{CI}=$ confidence Interval; $\mathrm{LVEF}=$ left ventricular ejection fraction; $\mathrm{BNP}=\mathrm{Brain}$

Natriuretic Peptide. * Adjusted for etiology, LVEF, ProBNP, baseline SBP and SBP reactivity to stress task. ${ }^{\dagger}$ Adjusted for the variables in the a priori planned model, as well as depression score and diuretic use.

To better understand how the magnitude of SBP reactivity was related to event free survival, SBP reactivity was examined in terms of tertiles, representing Low ( $4 \pm 6 \mathrm{~mm} \mathrm{Hg}$ ), Intermediate $(19 \pm 4 \mathrm{~mm} \mathrm{Hg})$ and High $(35 \pm 9 \mathrm{~mm} \mathrm{Hg})$ SBP reactivity to the public speaking task.

The clinical characteristics of participants comprising these tertiles are summarized in Table 3.

Table 3. Clinical Characteristics of study sample by Tertiles of SBP Reactivity.

\begin{tabular}{|c|c|c|c|c|}
\hline Characteristic (N=199) & $\begin{array}{c}\text { High Reactors } \\
(\mathrm{N}=67)\end{array}$ & $\begin{array}{c}\text { Intermediate } \\
\text { Reactors }(\mathrm{N}=65)\end{array}$ & $\begin{array}{c}\text { Low Reactors } \\
(\mathrm{N}=67)\end{array}$ & $P$ value \\
\hline Age (years) & $57.7 \pm 11.7$ & $56.0 \pm 12.5$ & $57.1 \pm 12.8$ & 0.73 \\
\hline BMI $\left(\mathrm{kg} / \mathrm{m}^{2}\right)$ & $30.5 \pm 6.49$ & $32.19 \pm 7.13^{\mathrm{a}, \mathrm{c}}$ & $30.5 \pm 7.06$ & 0.58 \\
\hline Race (\% White) & 45.2 & 46.2 & 58.5 & 0.14 \\
\hline Gender (\% Female) & 32.3 & 29.2 & 33.8 & 0.94 \\
\hline Pro BNP (pg/ml) & $1110.5 \pm 1597.4$ & $1830.7 \pm 2715.3$ & $2350.0 \pm 3480.2^{\mathrm{a}}$ & 0.03 \\
\hline LVEF (\%) & $33.4 \pm 10.1$ & $31.6 \pm 12.7$ & $29.9 \pm 10.9^{\mathrm{a}}$ & 0.10 \\
\hline Etiology (\% ischemic) & 40.3 & 44.6 & 43.1 & 0.91 \\
\hline Diabetes (\%) & 32.3 & 46.2 & $50.8^{\mathrm{a}}$ & 0.07 \\
\hline Beta Blocker (\%) & 90.3 & 89.2 & 83.1 & 0.50 \\
\hline
\end{tabular}

${ }^{\mathrm{a}}$ - significantly different from high reactors $(p<.05) ;^{\mathrm{b}}-$ significantly different from intermediate

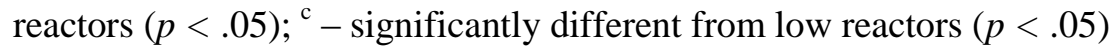


The Cox Proportional Hazards Regression Models were refit using Intermediate SBP Reactivity as the reference for understanding risk. Compared to Intermediate Reactivity, High SBP Reactivity was associated with lower risk of subsequent cardiovascular hospitalization or death $(\mathrm{HR}=.498,95 \%$ CI $[.335, .742], \mathrm{p}=.001)$, while Low SBP Reactivity was similar to Intermediate SBP Reactivity $(\mathrm{HR}=.879,95 \%$ CI $[.609,1.268], \mathrm{p}=.4901)$. These effects are illustrated by the Kaplan-Meier survival curves displayed in Figure 1.

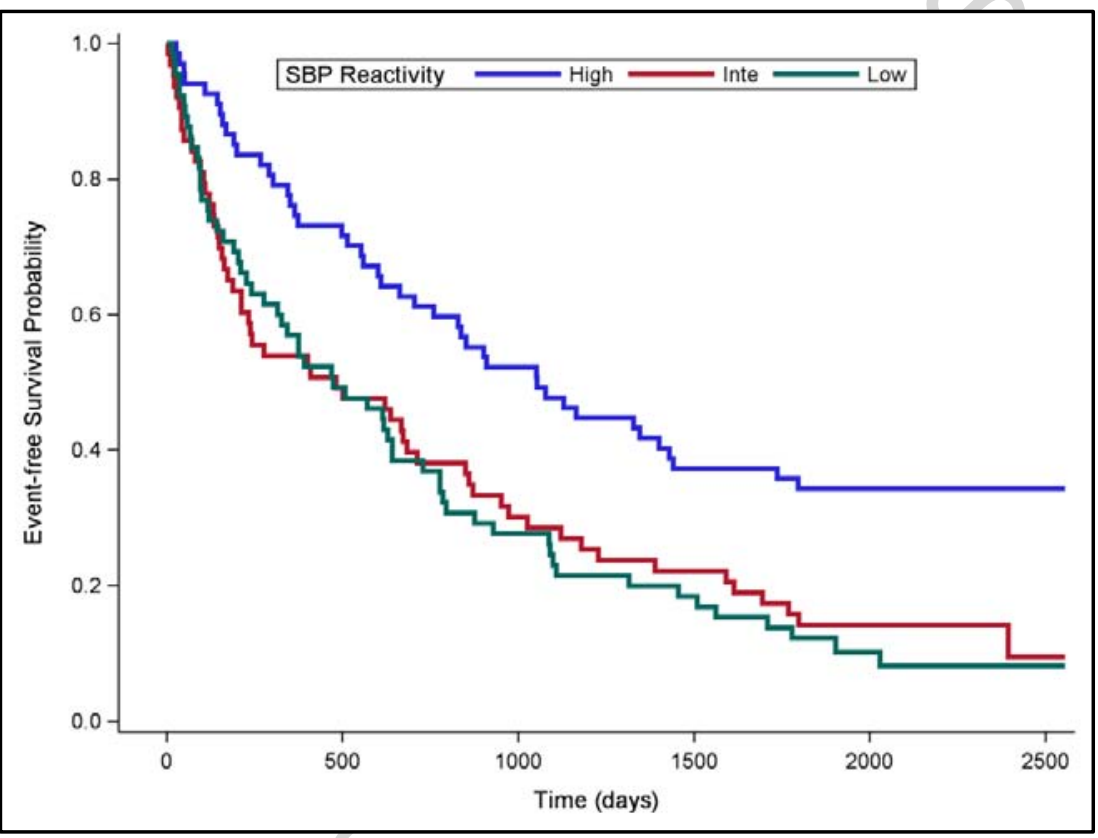

Figure 1. Event-free Survival by Systolic Blood Pressure Response in Tertiles Event-free survival over a median 5-year follow-up period for High (blue line), Intermediate (red line) and Low (green line) SBP reactivity to a public speaking stressor.

\section{Diastolic Blood Pressure (DBP) Reactivity.}

Results for DBP reactivity (Table 4), specified as a continuous variable, were similar to those for SBP reactivity. These regression models showed that greater DBP reactivity to public speaking was associated with lower risk of cardiovascular hospitalization or death (HR, 0.759; 95\% CI, $0.634-0.910 ; p<0.003$ ) in models which included etiology, LVEF, NT-proBNP and 
resting DBP. Extended models that added BDI depression scores and use of diuretics confirmed that elevated DBP reactivity was robustly associated with lower risk of cardiovascular hospitalization or death (HR, 0.765; 95\% CI, $0.638-0.919 p=0.004)$.

Table 4. Diastolic Blood Pressure Response to Mental Stress: Cox Proportional Regression Analyses for Death or Cardiac Hospitalization.

\begin{tabular}{|lcccc|}
\hline Variable & $\begin{array}{c}\text { Planned Model } \\
(\mathbf{9 5 \%} \mathbf{C I})\end{array}$ & P Value $^{*}$ & $\begin{array}{c}\text { Extended Model }^{\dagger} \text { HR } \\
(\mathbf{9 5 \%} \text { CI })\end{array}$ & P Value \\
\hline Etiology & $1.648(1.173-2.316)$ & $\mathbf{0 . 0 0 4}$ & $1.687(1.204-2.363)$ & $\mathbf{0 . 0 0 2}$ \\
LVEF/10 & $0.845(0.722-0.989)$ & $\mathbf{0 . 0 3 6}$ & $0.825(0.702-0.969)$ & $\mathbf{0 . 0 2 0}$ \\
ProBNP/1000 & $1.072(1.022-1.124)$ & $\mathbf{0 . 0 0 4}$ & $1.081(1.030-1.135)$ & $\mathbf{0 . 0 0 2}$ \\
Baseline DBP/10 & $1.002(0.853-1.176)$ & 0.985 & $1.016(0.864-1.196)$ & 0.846 \\
DBP Reactivity /10 & $0.759(0.634-0.910)$ & $\mathbf{0 . 0 0 3}$ & $0.765(0.638-0.919)$ & $\mathbf{0 . 0 0 4}$ \\
Depression & - & - & $1.033(1.011-1.055)$ & $\mathbf{0 . 0 0 3}$ \\
Diuretics & - & - & $2.083(1.014-4.278)$ & $\mathbf{0 . 0 4 6}$ \\
\hline
\end{tabular}

$\mathrm{HR}=$ Hazard ratio; $\mathrm{CI}=$ confidence Interval; $\mathrm{LVEF}=$ left ventricular ejection fraction; $\mathrm{BNP}=\mathrm{Brain}$

Natriuretic Peptide. * Adjusted for etiology, LVEF, ProBNP, baseline DBP and DBP reactivity to stress task. ${ }^{\dagger}$ Adjusted for the variables in the a priori planned model, as well as depression score and diuretic use.

Again, to better understand how DBP reactivity was related to event free survival, tertiles, representing Low $(5 \pm 4 \mathrm{~mm} \mathrm{Hg})$, Intermediate $(14 \pm 3 \mathrm{~mm} \mathrm{Hg})$ and High $(26 \pm 5 \mathrm{~mm} \mathrm{Hg})$ DBP reactivity were examined. The clinical characteristics of participants comprising these tertiles are summarized in Table 5.

Table 5. Clinical Characteristics of study sample by Tertiles of DBP Reactivity.

\begin{tabular}{|c|c|c|c|c|}
\hline Characteristic $(\mathrm{N}=199)$ & $\begin{array}{l}\text { High Reactors } \\
(\mathrm{N}=63)\end{array}$ & $\begin{array}{c}\text { Intermediate } \\
\text { Reactors }(\mathrm{N}=71)\end{array}$ & $\begin{array}{c}\text { Low Reactors } \\
(\mathrm{N}=66)\end{array}$ & $P$ value \\
\hline Age (years) & $56.6 \pm 12.4$ & $57.5 \pm 12.7$ & $56.6 \pm 12.8$ & 0.89 \\
\hline BMI $\left(\mathrm{kg} / \mathrm{m}^{2}\right)$ & $31.0 \pm 6.75$ & $31.6 \pm 7.60$ & $31.3 \pm 6.61$ & 0.90 \\
\hline Race (\% White) & 52.4 & 50.8 & 47.0 & 0.82 \\
\hline Gender (\% Female) & 30.2 & 33.8 & 31.8 & 0.90 \\
\hline Pro BNP (pg/ml) & $1236.1 \pm 2023.0$ & $1761.9 \pm 3048.7$ & $2127.6 \pm 2887.9$ & 0.17 \\
\hline LVEF (\%) & $33.3 \pm 10.7$ & $31.2 \pm 12.3$ & $32.3 \pm 11.0^{\mathrm{a}}$ & 0.49 \\
\hline Etiology (\% ischemic) & 38.1 & 46.5 & 45.5 & 0.58 \\
\hline Diabetes (\%) & 34.9 & 40.8 & $56.1^{\mathrm{a}}$ & 0.04 \\
\hline Beta Blocker (\%) & 92.1 & 81.7 & 89.4 & 0.17 \\
\hline
\end{tabular}

${ }^{\mathrm{a}}$ - significantly different from high reactors $(p<.05){ }^{\mathrm{b}}{ }^{\mathrm{b}}$ - significantly different from intermediate reactors $(p<.05) ;{ }^{\mathrm{c}}-$ significantly different from low reactors $(p<.05)$ 
Compared to Intermediate DBP Reactivity, High DBP Reactivity was marginally associated with lower risk of subsequent cardiovascular hospitalization or death $(\mathrm{HR}=.767$, 95\% CI [.515, 1.14], $\mathrm{p}=.193)$, while Low DBP Reactivity was associated with greater risk (HR $=1.49,95 \% \mathrm{CI}[1.027,2.155], \mathrm{p}=.0359)$. These effects are illustrated by the Kaplan-Meier survival curves displayed in Figure 2.

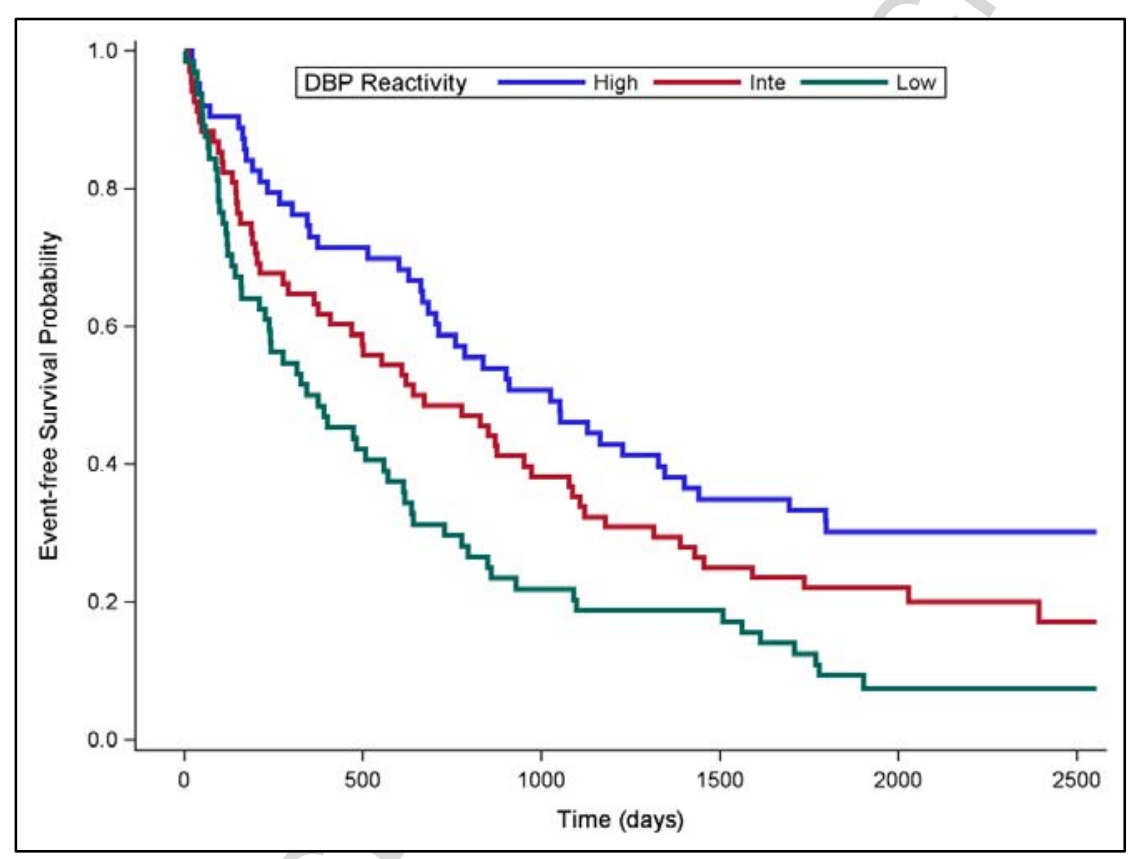

Figure 2. Event-free Survival by Diastolic Blood Pressure Response in Tertiles Event-free survival over a median 5-year follow-up period for High (blue line), Intermediate (red line) and Low (green line) DBP reactivity to a public speaking stressor.

\section{Heart Rate Reactivity}

In contrast to $\mathrm{BP}$, elevated heart rate reactivity to public speaking was not clearly associated with lower incidence of cardiovascular hospitalization or death (HR, 0.813; 95\% CI, $0.613-1.078 ; p=0.15$ ) in models which included etiology, LVEF, ProBNP and Baseline heart rate (Table 6). In the extended model for heart rate, only depression met criteria for inclusion; however, results for heart rate were virtually unchanged $(\mathrm{HR}=0.816 ; 95 \% \mathrm{CI}, 0.614-1.085 ; p=$ $0.162)$. 
Table 6. Heart Rate Response to Mental Stress: Cox Proportional Regression Analyses for Death or Cardiac Hospitalization.

\begin{tabular}{|lcccc|}
\hline Variable & $\begin{array}{c}\text { Planned Model } \\
(\mathbf{9 5 \%} \text { CI })\end{array}$ & P Value $^{*}$ & $\begin{array}{c}\text { Extended Model } \\
(\mathbf{9} \text { HR }\end{array}$ & $\begin{array}{c}\text { P } \\
\text { Value }\end{array}$ \\
\hline Etiology & $1.783(1.286-2.472)$ & $\mathbf{0 . 0 0 1}$ & $1.780(1.281-2.474)$ & $\mathbf{0 . 0 0 1}$ \\
LVEF/10 & $0.809(0.691-0.947)$ & $\mathbf{0 . 0 0 9}$ & $0.797(0.677-0.938)$ & $\mathbf{0 . 0 0 6}$ \\
ProBNP/1000 & $1.065(1.015-1.117)$ & $\mathbf{0 . 0 1 0}$ & $1.077(1.025-1.131)$ & $\mathbf{0 . 0 0 3}$ \\
Baseline Heart Rate/10 & $1.266(1.086-1.476)$ & $\mathbf{0 . 0 0 3}$ & $1.233(1.058-1.437)$ & $\mathbf{0 . 0 0 7}$ \\
Heart Rate Reactivity/10 & $0.813(0.613-1.078)$ & 0.150 & $0.816(0.614-1.085)$ & 0.162 \\
Depression & - & - & $1.033(1.010-1.055)$ & $\mathbf{0 . 0 0 4}$ \\
\hline
\end{tabular}

$\mathrm{HR}=$ Hazard ratio; $\mathrm{CI}=$ confidence Interval; $\mathrm{LVEF}=$ left ventricular ejection fraction; $\mathrm{BNP}=\mathrm{Brain}$

Natriuretic Peptide. * Adjusted for etiology, LVEF, ProBNP, baseline heart rate and heart rate reactivity to stress task. ${ }^{\dagger}$ Adjusted for the variables in the a priori planned model, as well as depression score.

\section{DISCUSSION}

In a study sample of stable HF outpatients with reduced LVEF, we examined whether cardiovascular reactivity to a laboratory-based simulated public speaking challenge was associated with subsequent risk of adverse clinical outcomes, defined by the composite endpoint of cardiovascular hospitalization or death. The results showed that greater BP reactivity was associated with a lower risk of adverse clinical outcomes, even after taking into account established risk factors. For SBP reactivity, patients comprising the highest one third of the distribution of SBP responses to the challenge were at approximately half the hazard of an adverse event compared to those exhibiting less marked SBP increases. For DBP, the associations with reactivity were directionally similar, but most marked when contrasting those exhibiting the lowest DBP reactivity, for whom the hazard of an adverse event was about 50\% greater compared to those exhibiting more robust DBP increases.

In contrast to the widely held viewpoint that high cardiovascular reactivity increases the risk of developing or exacerbating CVD (4), our findings suggest that for patients with HF and reduced LVEF, high BP reactivity is associated with lower risk, and indeed low BP reactivity is associated with increased risk. In this respect, our observations show an overall pattern that is 
consistent with the findings reported by Kupper and colleagues who found low DBP reactivity to be associated with increased risk of mortality in a study sample of $100 \mathrm{HF}$ patients with reduced LVEF (9). While the prevailing research hypothesis regarding cardiovascular reactivity has been that greater reactivity is deleterious to cardiovascular health, a more recent body of evidence has brought this unidirectional conceptualization into question. For example, attenuated cardiovascular reactivity has been observed in individuals who display health behaviors associated with heightened CVD risk, including obesity, eating disorders, smoking and substance abuse (14-19). Depression, which recently has been recognized as another risk factor for the development and exacerbation of CVD (20), also has been found to be characterized by blunted cardiovascular reactivity (16, 21-23). These findings highlight the issue of whether stress reactivity's link to CVD is a pathophysiologic mechanism, or more simply a bio-behavioral risk marker (24). Results of the present study suggest that the answer to this question may be dependent upon the population under study. In patients with borderline hypertension, for example, there is a characteristic BP hyper-reactivity to laboratory-based psychological challenge that is related to the subsequent development of hypertension (25). Potential mechanisms include metabolic autoregulation leading to vascular hypertrophy and vascular rarefaction (26), and SNS overdrive resulting in down-regulation of cardiac and vascular betaadrenergic receptors (27), all promoting a hemodynamic shift to elevated systemic vascular resistance that results in sustained hypertension. High BP reactivity also has been linked to adverse outcomes in patients with stable coronary heart disease (CHD) $(7,8)$. These patients not only show increased blood pressure and heart rate responses during laboratory mental stress testing, but also may be more likely to exhibit myocardial ischemia. This is presumably a manifestation of increased myocardial oxygen demands accompanied by compromised oxygen 
supply caused by SNS-mediated vasoconstriction of diseased coronary vessels $(28,29)$.

Provocation of myocardial ischemia in CHD patients has been shown to be an independent predictor of adverse clinical events, and also may reflect a mechanism that increases vulnerability to psychological stress in patients with $\operatorname{CHD}(30,31)$. Stress-induced myocardial ischemia is typically abolished following surgical coronary revascularization. In a study of 521 CHD patients who had undergone $\mathrm{CABG}$, high cardiovascular reactivity was associated with a reduced risk of clinical cardiovascular events (32). The authors interpreted this finding as indicative of the ability of the restored left ventricle to respond to the challenge of a mental stress task. We speculate that high BP reactivity in HF patients with reduced EF is also a negative risk marker by virtue of it representing left ventricular functional reserve that becomes apparent under the laboratory-evoked circumstance of psychological challenge. From this perspective, a robust increase in BP to psychological challenge is conceptualized as an adaptive healthy response that is summoned by the BP seeking properties of the central nervous system (33).

Examination of the Kaplan-Meier event-free survival curves (Figures $1 \& 2$ ) shows that the separation associated with BP reactivity emerged quite early in the clinical follow-up phase that succeeded the $\mathrm{CV}$ reactivity assessment. This observation is consistent with the interpretation that a robust BP response is indicative of a relatively healthy cardiac functional capacity, while a weak BP response may indicate limited cardiac reserve. Indeed, participants categorized as high BP reactors tended to have somewhat less severe HF disease biomarkers (Tables $3 \& 5$ ). However, our statistical models controlled for established risk factors, including HF disease severity, comorbidities, and medication use, thereby indicating the BP reactivity was independently related to clinical outcomes. The laboratory mental stress test protocol may therefore reveal the capacity for cardiovascular adaptation to environmental challenges that may 
further stratify HF disease severity beyond that provided by established biomarkers such as NTproBNP and LVEF.

The ability to adapt to physical challenge has been studied much more widely in HF patients. Cardiopulmonary exercise testing is considered the gold standard for the assessment of functional capacity, and is a predictor of mortality independent of other established biomarkers (34). The six-minute walk test has also been used as a simple approach to assessing functional capacity that also can help stratify risk in HF patients and guide their medical management (35). Unfortunately, we did not assess functional capacity using either of these approaches, so it is unknown whether cardiovascular reactivity to psychological challenge may provide unique risk stratification compared to that provided by physical assessments of functional capacity.

Several additional limitations should be considered when assessing our study observations. Participants were stable HF outpatients taking a broad range of cardiovascular medications that may have impacted the study findings. Although medications and comorbidities were addressed in statistical models, their potential effects cannot be completely accounted for. Notably, approximately $90 \%$ of the study participants were taking beta-blocker medications, which would limit heart rate responses to the psychological challenge, but leave BP responses unaltered (36). Therefore, our findings for BP but not heart rate reactivity may be due, in part, to the effects of these medications. Another important limitation of our study design is the uncertainty as to whether our observations indicate causal relationships between $\mathrm{CV}$ reactivity and adverse clinical outcomes. Indeed, it is unlikely that a highly reactive response conveys some cardio-protective function in the context of HF, but more likely that it reflects a physiological response to a psychological challenge that is a marker of the ability of the heart to engender an adaptive physiological adjustment to an environmental demand. Importantly, 
attenuated $\mathrm{CV}$ reactivity to mental stress was explanatory of adverse outcomes independently of established prognostic markers. Further research is needed to determine whether CV reactivity may provide a novel and unique marker of left ventricular systolic reserve that may be useful in risk stratification. 
Disclosure: None

Acknowledgements: This study was supported by Grants HL61784 and HL121708 from the National Heart, Lung, and Blood Institute, National Institutes of Health, Bethesda, MD, and grant M01-RR-30 from the General Clinical Research Center program, National Center for Research Resources, National Institutes of Health. 


\section{REFERENCES}

1. Cannon WB. Bodily Changes in pain, Hunger, Fear and Rage. New York: Appleton; 1915.

2. Lovallo WR, Gerin W. Psychophysiological reactivity: mechanisms and pathways to cardiovascular disease. Psychosom Med. 2003; 65:36-45.

3. Schwartz AR, Gerin W, Davidson KW, Pickering TG, Brosschot JF, Thayer JF, et al. Toward a causal model of cardiovascular responses to stress and the development of cardiovascular disease. Psychosom Med. 2003; 65:22-35.

4. Chida Y, Steptoe A. Greater cardiovascular responses to laboratory mental stress are associated with poor subsequent cardiovascular risk status: a meta-analysis of prospective evidence. Hypertension. 2010; 55:1026-32.

5. Taylor RS, Brown A, Ebrahim S, Jolliffe J, Noorani H, Rees K, et al. Exercise-based rehabilitation for patients with coronary heart disease: systematic review and meta-analysis of randomized controlled trials. Am J Med. 2004; 116:682-92.

6. Treiber FA, Kamarck T, Schneiderman N, Sheffield D, Kapuku G, Taylor T. Cardiovascular reactivity and development of preclinical and clinical disease states. Psychosom Med. 2003; 65:46-62.

7. Krantz DS, Santiago HT, Kop WJ, Bairey Merz CN, Rozanski A, Gottdiener JS. Prognostic value of mental stress testing in coronary artery disease. Am J Cardiol. 1999; 84:1292-7.

8. Manuck SB, Olsson G, Hjemdahl P, Rehnqvist N. Does Cardiovascular Reactivity to Mental Stress Have Prognostic Value in Postinfarction Patients - a Pilot-Study. Psychosomatic Medicine. 1992; 54:1028.

9. Kupper N, Denollet J, Widdershoven J, Kop WJ. Cardiovascular reactivity to mental stress and mortality in patients with heart failure. JACC Heart Fail. 2015; 3:373-82.

10. Beck AT, Beamesderfer A. Assessment of depression: the depression inventory. Modern Problems of Pharmacopsychiatry. 1974; 7:151-69.

11. Beck AT, Steer RA, Garbin MG. Psychometric properties of the Beck Depression Inventory: Twenty-five years of evaluation. Clinical Psychology Review. 1988; 8:77-100.

12. O'Connor CM, Jiang W, Kuchibhatla M, Mehta RH, Clary GL, Cuffe MS, et al. Antidepressant use, depression, and survival in patients with heart failure. Arch Intern Med. 2008; 168:2232-7.

13. Sherwood A, Blumenthal JA, Hinderliter AL, Koch GG, Adams KF, Jr., Dupree CS, et al. Worsening depressive symptoms are associated with adverse clinical outcomes in patients with heart failure. J Am Coll Cardiol. 2011; 57:418-23.

14. al'Absi M, Wittmers LE, Erickson J, Hatsukami D, Crouse B. Attenuated adrenocortical and blood pressure responses to psychological stress in ad libitum and abstinent smokers. Pharmacology, biochemistry, and behavior. 2003; 74:401-10.

15. Phillips AC, Der G, Hunt K, Carroll D. Haemodynamic reactions to acute psychological stress and smoking status in a large community sample. International Journal of Psychophysiology. 2009; 73:273-8. 16. Phillips AC. Blunted cardiovascular reactivity relates to depression, obesity, and self-reported health. Biological psychology. 2011; 86:106-13.

17. Panknin TL, Dickensheets SL, Nixon SJ, Lovallo WR. Attenuated Heart Rate Responses to Public Speaking in Individuals With Alcohol Dependence. Alcoholism: Clinical and Experimental Research. 2002; 26:841-7.

18. Lovallo WR, Dickensheets SL, Myers DA, Thomas TL, Nixon SJ. Blunted Stress Cortisol Response in Abstinent Alcoholic and Polysubstance-Abusing Men. Alcoholism: Clinical and Experimental Research. 2000; 24:651-8.

19. Ginty AT, Phillips AC, Higgs S, Heaney JL, Carroll D. Disordered eating behaviour is associated with blunted cortisol and cardiovascular reactions to acute psychological stress.

Psychoneuroendocrinology. 2012; 37:715-24. 
20. Watkins LL, Koch GG, Sherwood A, Blumenthal JA, Davidson JR, O'Connor C, et al. Association of anxiety and depression with all-cause mortality in individuals with coronary heart disease. J Am Heart Assoc. 2013; 2:e000068.

21. Brinkmann K, Schüpbach L, Joye IA, Gendolla GHE. Anhedonia and effort mobilization in dysphoria: Reduced cardiovascular response to reward and punishment. International Journal of Psychophysiology. 2009; 74:250-8.

22. Carroll D, Phillips AC, Hunt K, Der G. Symptoms of depression and cardiovascular reactions to acute psychological stress: Evidence from a population study. Biological psychology. 2007; 75:68-74.

23. de Rooij SR, Schene AH, Phillips DI, Roseboom TJ. Depression and anxiety: Associations with biological and perceived stress reactivity to a psychological stress protocol in a middle-aged population. Psychoneuroendocrinology. 2010; 35:866-77.

24. Krantz DS, Manuck SB. Acute psychophysiologic reactivity and risk of cardiovascular disease: a review and methodologic critique. Psychol Bull. 1984; 96:435-64.

25. Sherwood A, Hinderliter AL, Light KC. Physiological determinants of hyperreactivity to stress in borderline hypertension. Hypertension25(3):384-90. 1995.

26. Folkow B. Physiological aspects of primary hypertension. Physiol Rev. 1982; 62:347-504.

27. Sherwood A, Hill LK, Blumenthal JA, Johnson KS, Hinderliter AL. Race and sex differences in cardiovascular alpha-adrenergic and beta-adrenergic receptor responsiveness in men and women with high blood pressure. J Hypertens. 2017; 35:975-81.

28. Blumenthal JA, Jiang W, Waugh RA, Frid DJ, Morris JJ, Coleman RE, et al. Mental stress-induced ischemia in the laboratory and ambulatory ischemia during daily life. Association and hemodynamic features. Circulation. 1995; 92:2102-8.

29. Rozanski A, Bairey CN, Krantz DS, Friedman J, Resser KJ, Morell M, et al. Mental stress and the induction of silent myocardial ischemia in patients with coronary artery disease. The New England Journal of Medicine. 1988; 318:1005-12.

30. Jiang W, Babyak M, Krantz DS, Waugh RA, Coleman RE, Hanson MM, et al. Mental stress-induced myocardial ischemia and cardiac events. JAMA: The Journal of the American Medical Association. 1996; 275:1651-6.

31. Sheps DS, McMahon RP, Becker L, Carney RM, Freedland KE, Cohen JD, et al. Mental stressinduced ischemia and all-cause mortality in patients with coronary artery disease: Results from the psychophysiological investigations of myocardial ischemia study. Circulation. 2002; 105:1780-4.

32. Herd JA, Hoogwerf BJ, Barton F, Terrin ML, Czajkowski SM, Lindquist R, et al. Heart rate and blood pressure responses to mental stress and clinical cardiovascular events in men and women after coronary artery bypass grafting: the Post Coronary Artery Bypass Graft (Post-CABG) biobehavioral study. Am Heart J. 2003; 146:273-9.

33. Julius S. The blood pressure seeking properties of the central nervous system. J Hypertens. 1988; 6:177-85.

34. Costa HS, Lima MM, de Sousa GR, de Souza AC, Alencar MC, Nunes MC, et al. Functional capacity and risk stratification by the Six-minute Walk Test in Chagas heart disease: comparison with Cardiopulmonary Exercise Testing. Int J Cardiol. 2014; 177:661-3.

35. Wegrzynowska-Teodorczyk K, Rudzinska E, Lazorczyk M, Nowakowska K, Banasiak W, Ponikowski $\mathrm{P}$, et al. Distance covered during a six-minute walk test predicts long-term cardiovascular mortality and hospitalisation rates in men with systolic heart failure: an observational study. J Physiother. 2013; 59:177-87.

36. Sherwood A, Allen MT, Obrist PA, Langer AW. Evaluation of beta-adrenergic influences on cardiovascular and metabolic adjustments to physical and psychological stress.

Psychophysiology23(1):89-104. 1986. 